\title{
Designing and Development of Denim Fabrics: Part 1 - Study the Effect of Fabric Parameters on the Fabric Characteristics for Women's Wear Kumar $\mathbf{S}^{1}$, Chatterjee $\mathbf{K}^{1}$, Padhye $\mathbf{R}^{2}$ and Nayak $\mathbf{R}^{2 *}$
}

${ }^{1}$ Technological Institute of Textiles and Sciences Bhiwani, India 127021

${ }^{2}$ School of Fashion and Textiles, RMIT University, Brunswick, Australia 3056

\begin{abstract}
The performance of a garment during its usage is very important for consumers. Performance as such is a very wide term and may range from satisfying the requirements during its use to the durability. Comfort is also considered by many consumers today as one of the performance requirements. For stretchable denim fabric, the fit related comfort lies in the ability of the material to be stretched when a load is applied according to body movements and retain to its original length. While designing the stretch denim, fabric weight and weave plays important role for comfort, performance and fashion. In this study, the effect of fabric parameters such as areal density, Lycra content and weave on characteristics of stretchable denim fabrics were investigated. Various properties such as thickness, tensile strength, flexural rigidity, stretch and recovery properties and air permeability of the fabrics were evaluated. The test results revealed that increasing the fabric weight increased fabric warp tensile strength, compressibility, stretch and recovery, whereas the flexural rigidity, weft tensile strength and air permeability were decreased. As Lycra contents in fabric increased, fabric thickness was increased which resulted in higher flexural rigidity of fabric. Fabric construction and weave also influenced the fabric flexural rigidity and air permeability related to performance and comfort of stretchable denim fabric.
\end{abstract}

Keywords: Stretch denim; Lycra; Fabric compression; Air permeability; Stretchability; Elastic recovery

\section{Introduction}

Denim, the favourite fabric of the youngsters has indeed come a long way. The consumer's choice, although unstable and unpredictable, it has remained almost the same while selecting denim for their fashion item [1-4]. The scope for denim wear is increasing tremendously every year and its worldwide market share has increased unpredictably in the last few decades. Recently the fashion trend is moving from denim to stretch denim (denim with Lycra) [5]. Stretch denim usually incorporates an elastic component (such as elastane) into the fabric to allow a degree of stretchability in garments [6,7]. Denim is a heavy woven fabric made from $100 \%$ cotton coarse indigo dyed warp and grey weft yarn [8-10]. The traditional denim is rather hard and high density fabrics with high mass per unit area. Twill weaves such as three-up-one-down (3/1) and two-up-one-down $(2 / 1)$ are predominantly used for denim construction [11-13]. Denim is available in attractive indigo blue shades and is made for a variety of applications and in a wide range of qualities. Denim is comfortable, fashionable, affordable and durable for which it is popular in all the age groups.

Denim is available in different weights ranging from $200-300 \mathrm{~g} / \mathrm{m}^{2}$ which are categorized as light denim to $300-600 \mathrm{~g} / \mathrm{m}^{2}$, known as heavy denim. Denim's durability lies in the combination of the yarn and the weave. The consumer's today need durability and comfort in their fashion items including denim [14-17]. Twill weaves have good abrasion resistance, meaning the fabric will absorb a lot of friction before it breaks apart. The reason for such great durability is the way the yarns are woven together: one set of yarns floats over another in 2-5 (generally 2-3) sets of yarns at regular intervals to create a diagonal textured fabric surface. It is these yarn "floats" that absorb the abrasion. Denim has always been used for very durable outdoor work clothing because of its weight, rigidity and thickness. Denim is a good choice for casual jackets, skirts and jeans. In recent years, the advancements in garment-finishing techniques have led to easy processing and subsequently its use has broadened into different lifestyles. The clothing made of denim can be often sold in high prices depending on its fit, ornamentation, finishing and brand [18].
The stretchable denim fabrics give the elasticity to fabric so that it closely fit to body without restricting the body movement [1921], hence providing wear comfort [22-24]. Lycra yarn is added to denim to increase its stretch and recovery properties [25]. Generally, adding 1-5\% of Lycra with cotton will stretch the fabric over the body providing a more comfortable fit. For example, Rahman [26] studied the effect of spandex ratio on fabric physical and mechanical properties such as: breaking strength, breaking extension, shrinkage and fabric growth [27-30]. The findings of this study revealed that the ratio of Lycra had a significant influence on the physical properties of woven denim fabrics. Özdil [7] had studied the stretch and bagging properties of denim fabrics containing different amounts of elastane. The test results revealed that increasing the amount of elastane in denim fabric enhanced comfort properties related to stretch.

Core spun yarn can also be used as filling in which core part is Lycra filament and sheath fibres cotton, to improve the stretchability of denim $[7,25,31,32]$. The performance and comfort factors of these garments during use are very important. Generally, the comfortable stretching of fabrics according to body movements as well as recovery after stretching, are the desirable properties. In recent years, due to the demand for more comfortable clothing, elastane-containing denim fabrics are becoming increasingly popular. Some of the earlier studies focused on the effects of Lycra on physical and stretch properties of the denim fabrics. Some recent studies focused on the anti-bacterial

*Corresponding author: Rajkishore Nayak, School of Fashion and Textiles RMIT University, Brunswick, Australia 3056, Tel: +61 039925 9349; E-mail: rajkishore.nayak@rmit.edu.au

Received June 27, 2016; Accepted August 12, 2016; Published August 18, 2016

Citation: Kumar S, Chatterjee K, Padhye R, Nayak R (2016) Designing and Development of Denim Fabrics: Part 1 - Study the Effect of Fabric Parameters on the Fabric Characteristics for Women's Wear. J Textile Sci Eng 6: 265. doi: 10.4172/2165-8064.1000265

Copyright: (C) 2016 Kumar S, et al. This is an open-access article distributed under the terms of the Creative Commons Attribution License, which permits unrestricted use, distribution, and reproduction in any medium, provided the original author and source are credited. 
Citation: Kumar S, Chatterjee K, Padhye R, Nayak R (2016) Designing and Development of Denim Fabrics: Part 1 - Study the Effect of Fabric Parameters on the Fabric Characteristics for Women's Wear. J Textile Sci Eng 6: 265. doi: 10.4172/2165-8064.1000265

Page 2 of 5

properties of denim fabric [33]. However, limited research has been done on the effect of Lycra content and weaves on the performance and comfort properties of the denim fabric.

Hence, this research aims to investigate the effect of fabric areal density, Lycra content and weave on stretch and recovery properties in addition to the physical and comfort properties. For this purpose, different properties of denim fabrics introduced with varying amounts of elastane incorporated into core spun yarns in the weft direction were measured. The comfort properties related to stretch, performance factors and comfort related to air permeability were measured. Hence, the effect of amount of Lycra on fabric thickness, flexural rigidity, tensile strength, and stretch and recovery properties were evaluated. The effect of weave on the physical and stretch properties of the fabric was also investigated.

\section{Experimental}

\section{Materials}

Four denim fabrics were developed with varying amount of stretch (depending on the Lycra content) in the present study by keeping the GSM and weave same. The samples were abbreviated as L0, L1, L2 and L3 with $0,1,1.5$ and $2 \%$ of Lycra, respectively. The specifications of denim fabrics are shown in Table 1.

Numerical notations for different denim designs, such as $3 / 1$, denote what each warp yarn is doing relative to the filling yarns that it is interlacing with. In this case, each warp yarn is going "over" three picks and then "under" one pick. This would be verbally stated as " 3 by 1 " twill or " 3 by 1 " denim. At the next end or warp thread to the right, the same sequence is repeated but advanced up one pick. This advancing upward sequence continues, giving the characteristic feature of twill lines. In this case, the twill line is rising to the right and the fabric is classified as right hand twill (RHT) weave (Figure 1a). If the twill line is made to rise to the left, then the design is left hand twill (LHT) (Figure 1b). Broken twills are designed by breaking up the twill line at different intervals thus keeping it from being in a straight line.

For a more pronounced twill line in a denim fabric, the direction of twist in the warp yarn should be opposite to the twill direction in the fabric. For example, if "Z-twisted" yarn is woven into right hand twill, the twill line is less pronounced. If "S-twisted" yarn is woven into the same fabric, then the twill line is more pronounced. It must be remembered that only Z-twisted yarns are formed in open-end yarns, while ring-spun yarns have either " $Z$ " or " $S$ " twist. For this reason, open-end yarn can be used in left hand twills when a more pronounced twill line is desirable. Having the twist direction opposite from the direction of the twill line also tend to make the fabric handle a little softer.

\section{Methods}

Followings methods were used for testing the fabric samples. The details of the procedure and calculation of each testing is described below.
Conditioning: All the denim fabrics were evaluated in the greige form for the physical and other properties. Unless otherwise mentioned, the test specimens were conditioned at standard atmosphere of $20 \pm 2^{\circ}$ $\mathrm{C}$ temperature and $65 \pm 5 \%$ relative humidity $(\mathrm{RH})$ before performing any of the tests.

Fabric weight and thickness: The thickness of stretchable denim fabric was measured using a thickness tester (Karl Schroder KG) under $0.5 \mathrm{kPa}$ pressure following BS EN ISO 9073-2: 1997 standard. Thread density was measured by using a pick glass as per ISO 7211/2-1984. The weight per unit area $\left(\mathrm{g} / \mathrm{m}^{2}\right)$ was measured by using a circular specimen of $100 \mathrm{~cm}^{2}$ area following ISO 3801-1977 standard test method.

Compressibility and compression recovery: For the assessment of fabric compressibility and fabric compression recovery, fabric thickness was measured at higher pressures $(2.0$ and $4.0 \mathrm{kPa})$. Compressibility and compression recovery percentage was obtained using the following formula:

Compressibility $(\%)=100 \times\left(\mathrm{t}_{1}-\mathrm{t}_{2}\right) / \mathrm{t}_{1}$

Where, $\mathrm{t}_{1}=$ measured thickness at $0.5 \mathrm{kPa}, \mathrm{t}_{2}=$ measured thickness at $2.0 \mathrm{kPa}$

Compression recovery $(\%)=100 \times\left(t_{3}-t_{2}\right) /\left(t_{1}-t_{2}\right)$

Where, $\mathrm{t}_{1}=$ measured thickness at $0.5 \mathrm{kPa}, \mathrm{t}_{2}=$ measured thickness $\mathrm{t}$ at $2.0 \mathrm{kPa}$ and $\mathrm{t}_{3}=$ measured thickness at $4.0 \mathrm{kPa}$.

Flexural rigidity: The flexural rigidity is the measure of fabric stiffness. Denim fabrics samples were tested for flexural rigidity as per ASTM D1388-08. The principle of stiffness was based on the principle of cantilever bending of the fabric under its own mass. The test was done on a Shirley stiffness tester. Five samples of $20 \mathrm{~cm} \times 2.5 \mathrm{~cm}$ were cut from the fabric each in warp and weft direction. Ten readings were taken for each fabric sample in each of the warp and weft direction. The specifications of the stiffness testers is described in Table 2.

Fabric flexural rigidity was calculated by the following formula:

Flexural rigidity $(\mathrm{G})=\mathrm{W} \times \mathrm{C}^{3} \mathrm{mg}-\mathrm{cm}$

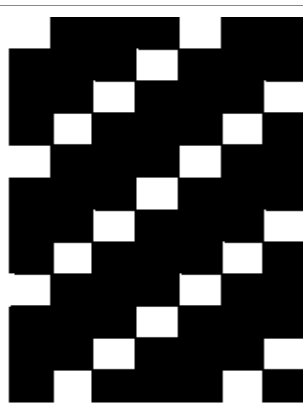

3/1 RHT

(a)

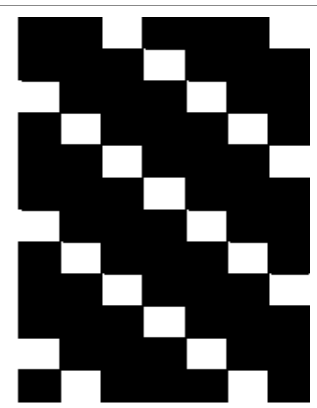

3/1 LHT

(b)
Figure 1: $3 / 1$ twill: (a) Right hand twill (RHT) and (b) left hand twill (LHT).

\begin{tabular}{|c|c|c|c|c|c|c|c|c|}
\hline \multirow{2}{*}{ Fabric Code } & \multirow{2}{*}{ Lycra content $(\%)$} & \multirow{2}{*}{ Fabric weight (GSM ) } & \multirow{2}{*}{ Fabric thickness $(\mathrm{mm})$} & \multirow{2}{*}{ Weave } & \multicolumn{2}{|c|}{ Thread density (threads/cm) } & \multicolumn{2}{|c|}{ Yarn linear density $(\mathrm{Ne})$} \\
\hline & & & & & Warp & Weft & Warp & Weft \\
\hline LO & 0.0 & 320 & 0.631 & 3/1 RHT & 28 & 26 & 14 & 12 \\
\hline L1 & 1.0 & 320 & 0.654 & 3/1 RHT & 28 & 26 & 14 & 12 \\
\hline L2 & 1.5 & 320 & 0.728 & 3/1 RHT & 28 & 26 & 14 & 12 \\
\hline L3 & 2.0 & 320 & 0.792 & 3/1 RHT & 28 & 26 & 14 & 12 \\
\hline
\end{tabular}

Table 1: Specifications of denim fabrics with different Lycra content. 
Where, $\mathrm{W}$ is fabric weight in $\mathrm{g} / \mathrm{cm}^{2}, \mathrm{C}$ is bending length in $\mathrm{cm}$.

Breaking strength: Breaking strength and elongation were tested on a universal tensile testing machine from Instron ${ }^{\bullet}$ at a traverse of 300 $\mathrm{mm} / \mathrm{min}$. Fabric samples with $25 \mathrm{~mm} \times 150 \mathrm{~mm}$ dimension were used and ASTM D 5035-11 (Standard test method for breaking force and elongation of textile fabrics (strip method)) was followed for the test. Five readings were taken for each fabric sample and the average values were reported.

Stretch properties: Fabric stretch properties are related with fabric extension and recovery when in use. Fabric stretch properties were tested as per ASTM D 3107-07. Test specimens of $65 \mathrm{~mm} \times 560 \mathrm{~mm}$ were cut from the fabric. Specimens from weft direction were hung on the apparatus after marking a $250 \mathrm{~mm}$ index in the central part of each specimen. A $1.8 \mathrm{~kg}$ load, which was hung according to the fabric weight in the bottom hanger, was applied to the sample three times and after the fourth application; the marked distance was measured. The samples were hung for 30 minutes, and the distance was measured once again. After that fabric samples were removed from the testing apparatus and were relaxed for 1 hour. Fabric stretch properties after cyclic loading were measured [34]. The total number of ten cycles was required at fixed load of fabric. Sample strip length was same as used in stretch testing of fabric. Fabric stretch, growth and elastic recovery values were calculated from these measured outcomes, as follows:

$$
\begin{aligned}
& \text { Fabric stretching }(\%)=\frac{B-A}{A} \times 100 \\
& \text { Fabric growth }(\%)=\frac{C-A}{A} \times 100 \\
& \text { Elastic recovery }(\%)=\frac{B-C}{B-A} \times 100
\end{aligned}
$$

Where, $\mathrm{A}$ is the distance marked between the upper and lower part of the fabric $(250 \mathrm{~mm}), \mathrm{B}$ is the distance between the marked points after hanging the sample for 30 minutes with the load (in $\mathrm{mm}$ ) and $\mathrm{C}$ is the distance between the marked points after 1 hour of relaxation.

Air permeability: Air permeability is a measure of how well the fabric allows air flow through it under a differential pressure between the two surfaces. Air permeability is defined as the volume of air in millilitres, which is passed in one second through $100 \mathrm{~mm}^{2}$ of a fabric at a pressure difference of $10 \mathrm{~mm}$ head of water. During the test, the specimen was clamped over an air inlet of the apparatus and air was sucked through it by means of a pump. The air valve is then adjusted to give a pressure drop across the fabric of $10 \mathrm{~mm}$ head of water and the air flow is then measured using a flow meter. Five specimens were used each with a test area of $508 \mathrm{~mm}^{2}(25.4 \mathrm{~mm}$ diameter $)$ and the mean air flow in cubic centimetre per square centimetre per second was calculated from the five results.

Statistical analysis: The difference between the average results for each test was estimated using the one-way analysis of variance (ANOVA) using Excel 2013 at the $p \leq 0.001$ level. The difference between the fabrics was significant when the $F$ value was higher than $\mathrm{F}_{\text {critical }} \mathrm{F}_{\text {critical }}$ is the value which the test results must exceed to reject the null hypothesis.

\begin{tabular}{|c|c|}
\hline Test parameters & Values \\
\hline Sample size & $20 \mathrm{~cm} \times 2.5 \mathrm{~cm}$ \\
\hline Angle of inclination of intersecting plane to horizontal & $41.5^{\circ}$ \\
\hline Load on test specimen & $10 \pm 2 \mathrm{~g} / \mathrm{cm}$ \\
\hline
\end{tabular}

Table 2: Specifications of Stiffness Tester.

\section{Results and Discussion}

\section{Effect of lycra content on fabric properties}

Compressibility and compression recovery: Fabric compressibility is one of the important parameters affecting the fabric mechanical properties. The compressional properties affect fabric's softness, fullness, smoothness and are related to fabric handle [35]. Fabric compressional properties depend on surface properties of fibre and yarns, lateral compressional properties of fibre and yarns, and the fabric structure. The effect of Lycra content on compressibility and compression recovery properties of denim fabric is graphically shown in Figure 2. It can be observed that the increase in Lycra content significantly affected the compressibility and compression recovery properties of the denim fabric samples. As the Lycra content increased, fabric compressibility increased. This can be attributed to the spring like behaviour of the Lycra fibre and its tendency to recover to its original dimensions after the load is being removed. The compression recovery of the denim fabrics also showed similar trend as compressibility. In addition with the increased Lycra content, the fabric thickness was increased as shown in Table 1, which resulted in the increase of the compressibility and compression recovery properties. From ANOVA analysis it was observed that there is a significant difference in fabric compressibility and compression recovery of the denim fabrics having different Lycra content $(\mathrm{F}=1290.92, \mathrm{p} \leq 0.001)$.

Flexural rigidity: Fabric flexural rigidity is a measure of the fabric stiffness. A fabric with higher flexural rigidity will be stiffer. The stiffness affects the fabric drape and tactile comfort. The fabric with very high stiffness may not be comfortable to wear and cannot bend as per the body contours. The effect of Lycra content on the flexural rigidity of the stretchable denim fabric is shown in Figure 3. It can be observed that the flexural rigidity of denim fabrics increased with the increase in the Lycra content both in the warp and weft direction. The filament structure of the Lycra made the yarn stiffer, which finally led to increased stiffness. Furthermore, it can be observed that as the as the thickness of the fabric was higher with higher Lycra content, this resulted in higher flexural rigidity. It is evident that the fabric handle becomes stiffer as the Lycra content in the structure of the fabric was increased. The higher flexural rigidity in warp direction can be attributed to the weft yarns containing Lycra having coil like structure and its tendency to recover to its initial dimension. The warp yarn has to come closer, which makes contraction in the fabric. Therefore, the larger flexural rigidity was observed in warp direction than weft direction of fabrics. From statistical analysis (oneway ANOVA) it can be observed that there is a significant difference

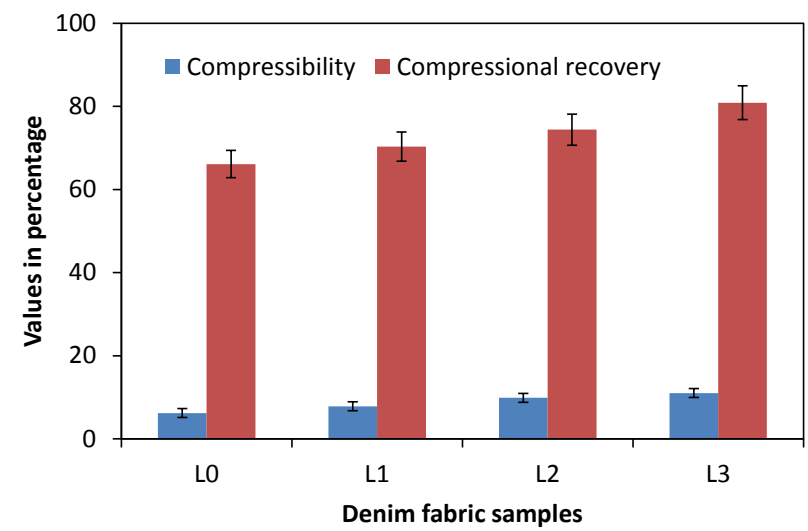

Figure 2: Effect of Lycra content on compressibility and compression recovery properties of denim fabric. 
Citation: Kumar S, Chatterjee K, Padhye R, Nayak R (2016) Designing and Development of Denim Fabrics: Part 1 - Study the Effect of Fabric Parameters on the Fabric Characteristics for Women's Wear. J Textile Sci Eng 6: 265. doi: 10.4172/2165-8064.1000265

between the fabric flexural rigidity of the denim fabric samples having different Lycra content $(\mathrm{F}=101220.81, \mathrm{p} \leq 0.001)$

Breaking strength: The breaking strength of a fabric is a measure of its performance during use [36]. The fabric used for the construction of particular clothing should be able to withstand the fatigue applied to it. A garment with insufficient breaking strength may fail during use, which can lead to the rejection of the garment. The effect of Lycra content on breaking strength in the direction of both warp and weft are shown in Figure 4. It can be observed that the braking strength of the fabric gradually increased in the warp direction with the Lycra content, whereas it decreased significantly in the weft direction with Lycra content. The increase in the breaking strength in the warp direction can be attributed to higher fabric assistance provided by the weft yarns with increased Lycra content. As the Lycra percentage was gradually increased, the additional amount of Lycra provided higher assistance to the warp yarn, resulting in increased warp-wise tensile strength. However, the decrease of the breaking strength in the weft direction can be attributed to the low strength of Lycra compared to cotton. Although Lycra is highly stretchable, it does not contribute to the strength of the fabric. It was observed that more Lycra content in fabrics reduced the fabric breaking strength than $100 \%$ cotton based fabrics (L0). This is one of the negative attribute of Lycra fibres as the stretchability is achieved with the compensation of the fabric strength. From statistical analysis (one-way ANOVA) it was observed that there is a significant difference in the breaking strength of the three experimental fabrics having different Lycra content $(\mathrm{F}=4013.55, \mathrm{p} \leq 0.001)$.

Stretch properties: Fabric stretchability indicates the property of the fabric that facilitates the body part movements. A fabric with higher stretch may follow the body movement easily. However once the force is being removed, the fabric should return to its original dimensions. The fabric containing Lycra are well known for their good stretchability and stretch recovery characteristics. Figure 5 shows the effect of Lycra content on stretchability and recovery properties of denim fabrics. It can be observed that the stretchability was increased with the Lycra content. As Lycra yarn possesses higher extensibility and elastic recovery, the increase in the stretchability was observed. The stretch recovery was also increased with increase of the Lycra content in the fabric due to the presence of Lycra. From ANOVA analysis it was observed that there is a significant difference in fabric stretch properties of the three denim fabrics having different Lycra content $(\mathrm{F}=408.02, \mathrm{p} \leq 0.001)$.

Air permeability: The air permeability of a fabric is the ability of the fabric to allow the atmospheric air to flow thorough the fabric and reach the skin. Depending on the usage of the fabric, the air permeability values are determined. For example, high air permeability may be a desired for clothing in hot climate. However, it may be negative in cold climates. The effect of Lycra content on air permeability of denim fabric is shown in Figure 6. It can be observed that the Lycra content has a profound effect on fabric air permeability. The higher value of air permeability is observed in the fabric with lower value of Lycra content and it decreased as the Lycra content was increased. As Lycra content increased in the fabric, contraction of the woven fabric was more, which made the fabric more compact and thicker, resulting in higher resistance to air flow. Hence, the higher amount of Lycra content can help in achieving higher stretchability, with reduced air permeability. The reduced air permeability may result in the lower water vapour resistance and hence cause discomfort to the wearer. However, as the fabrics are used in single layers the water vapour resistance, which is generally in the lower range for denim will be changing marginally [37]. From statistical analysis it was observed that there is a significant difference in fabric air permeability of the three denim fabrics having different Lycra content $(\mathrm{F}=3366.718, \mathrm{p} \leq 0.001)$.

\section{Conclusions}

The results obtained in this study indicated that the amount of Lycra has a significant influence on physical and elastic properties of denim fabrics. Fabric tensile strength was decreased in weft direction with Lycra content, while fabric tensile strength was increased in warp direction because of the higher fabric assistance by the weft yarns. As the fabric thickness increased, fabric compressibility, compression recovery and flexural rigidity increased. The compressibility, compression recovery increased as the Lycra content was increased in the fabric. The flexural rigidity was also increased with the increase in the amount of Lycra in the denim fabric. Furthermore, As the Lycra content was

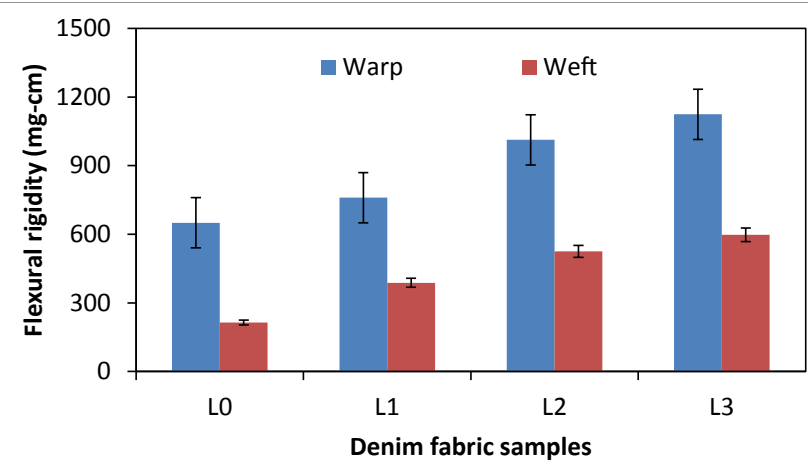

Figure 3: Effect of Lycra content on flexural rigidity of denim fabric.

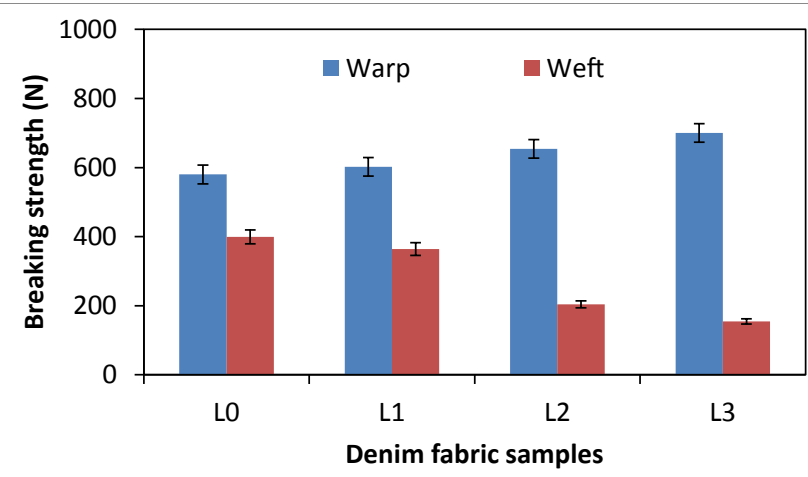

Figure 4: Effect of Lycra content on breaking strength of denim fabric.

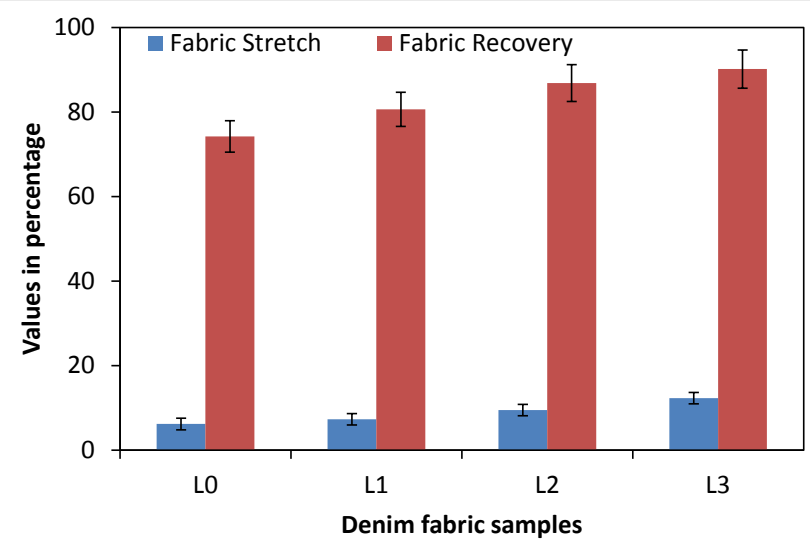

Figure 5: Effect of Lycra content on stretch properties of denim fabric. 
Citation: Kumar S, Chatterjee K, Padhye R, Nayak R (2016) Designing and Development of Denim Fabrics: Part 1 - Study the Effect of Fabric Parameters on the Fabric Characteristics for Women's Wear. J Textile Sci Eng 6: 265. doi: 10.4172/2165-8064.1000265

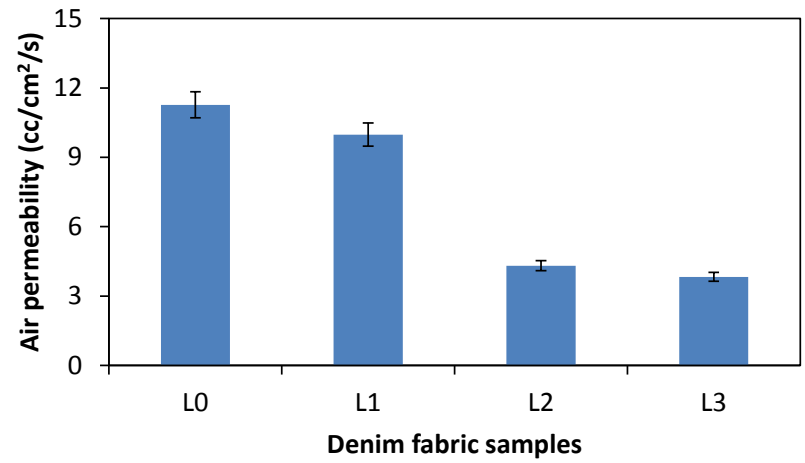

Figure 6: Effect of Lycra content on air permeability of denim fabric.

increased the air permeability and decreased significantly due to the fact that the fabrics become thicker and more compact with the increase in Lycra content in the woven fabrics. Statistical analysis proved that the difference between the results for the three fabric were significant for all the properties. As per the survey results, denim was preferred to be the first choice in the women's wear for style and fashion, which will be published in Part 2 of the paper.

\section{References}

1. Zervent Ünal B (2012) The prediction of seam strength of denim fabrics with mathematical equations. Journal of the Textile Institute 103: 744-751.

2. Nayak R, Padhye R (2015) Garment Manufacturing Technology. Elsevier.

3. Nayak R, Padhye R (2014) Introduction: the apparel industry, in Garment Manufacturing Technology. Elsevier.

4. Lee IY, Jeong EG, Kim SR, Bengelsdorff C, Kim SD (2015) Effects of biowashing and liquid ammonia treatment on the physical characteristics and hand of denim fabric. Coloration Technology 131: 192-199.

5. Kumar V, Nayak R (2014) Sewing performance of PV and PES air-jet textured sewing threads in denim fabrics. Journal of Textile and Apparel, Technology and Management 8: 1-12

6. El-Ghezal S, Babay A, Dhouib S, Cheikhrouhou M (2009) Study of the impact of elastane's ratio and finishing process on the mechanical properties of stretch denim. The Journal of Textile Institute 100: 245-253.

7. Özdil N (2008) Stretch and bagging properties of denim fabrics containing different rates of elastane. Fibres and Textiles in Eastern Europe 16: 66.

8. McLoughlin J, Hayes S, Paul R (2015) Cotton fibre for denim manufacture. Denim: Manufacture, Finishing and Applications.

9. Rahman O, Jiang Y, Liu WS (2010) Evaluative criteria of denim jeans: A crossnational study of functional and aesthetic aspects. The Design Journal 13: 291

10. Behera B, Chand S, Singh TG, Rathee P (1997) Sewability of denim International Journal of Clothing Science and Technology 9: 128-140.

11. Raina M, Gloy Y, Gries T (2015) Weaving technologies for manufacturing denim. Denim: Manufacture, Finishing and Applications.

12. Adanur S, Qi J (2008) Property analysis of denim fabrics made on air-jet weaving machine part I-Experimental system and tension measurements. Textile Research Journal 78: 3-9.

13. Glassner A (2002) Digital weaving-1, Computer Graphics and Applications. IEEE 22: 108-118.

14. Nayak R, Padhye R (2014) The care of apparel products, in Textiles and fashion: Materials, design and technology. Elsevier 799-822.

15. Nayak R (2009) Comfort properties of suiting fabrics. Indian Journal of Fibre and Textile Research 34: 122-128.

16. Morris M, Prato H (1981) Consumer perception of comfort, fit and tactile characteristics of denim jeans. Textile Chemist and Colorist 13: 24-30.

17. Wu J, Delong M (2006) Chinese perceptions of western-branded denim jeans: a Shanghai case study. Journal of Fashion Marketing and Management: An International Journal 10: 238-250

18. Nayak R, Padhye R, Wang L, Chatterjee K, Gupta S (2015) the role of mass customisation in the apparel industry. International Journal of Fashion Design, Technology and Education 8: 162-172.

19. Nayak R, Padhye R, Dhamija S, Kumar V (2013) Sewability of air-jet textured sewing threads in denim. Journal of Textile and Apparel Technology and Management 8: 1-11

20. 20. Kan C, Yuen C (2009) Evaluation of the performance of stretch denim fabric under the effect of repeated home laundering processes. International Journal of Fashion Design Technology and Education 2: 71-79.

21. Mourad M, Elshakankery M, Almetwally AA (2012) Physical and stretch properties of woven cotton fabrics containing different rates of spandex. Journal of American Science 8:(4)

22. Nayak R, Padhye R, Wang L (2015) How to Dress at Work, in Management and Leadership-A Guide for Clinical Professionals. Springer 241-255.

23. Chatterjee K, Das D, Nayak R, Kavita (2011) Study of handle and comfort properties of Poly-khadi, handloom and powerloom fabrics. Man-Made Textiles in India 39: 351-358.

24. Crowther $E$ (1985) Comfort and fit in $100 \%$ cotton-denim jeans. Journal of the Textile Institute 76: 323-338.

25. Nayak R, Padhye R, Gon DP (2010) Sewing performance of stretch denim Journal of Textile and Apparel Technology and Management 6: 1-9.

26. Rahman O (2011) Understanding consumers' perceptions and buying behaviours: Implications for denim jeans design. Journal of Textile and Appare Technology and Management 7: (1)

27. Lee JT, Kim MW, Song YS, Kang TJ, Youn JR (2010) Mechanical properties of denim fabric reinforced poly (lactic acid). Fibers and Polymers 11: 60-66.

28. Haghighat E, Etrati SM, Najar SS (2013) Modeling of needle penetration force in denim fabric. International Journal of Clothing Science and Technology 25 361-379.

29. Hua T, Tao XM, Cheng KPS, XU BG, Huang XX (2013) An experimental study of improving fabric appearance of denim by using low torque singles ring spun yarns. Textile Research Journal.

30. Sariisik, Merih (2004) Use of Cellulases and Their Effects on Denim Fabric Properties. AATCC review 4:(1).

31. Lou C, Chang CW, Lin JH, Lei CH, Hsing WH (2005) Production of a polyester core-spun yarn with spandex using a multi-section drawing frame and a ring spinning frame. Textile Research Journal 75: 395-401.

32. Jaouachi B Hassen MB, Sahnoun M, Sakli F (2010) Evaluation of wet pneumatically spliced elastic denim yarns with fuzzy theory. The Journal of Textile Institute 101: 111-119.

33. Sumithra M, Raaja NV (2012) Antibacterial efficacy analysis of Ricinus communis, Senna auriculata and Euphorbia hirta extract treated on the four variant of denim fabric against Escherichia coli and Staphylococcus aureus. Journal of Textile Science and Engineering.

34. Mukhopadhyay A, Nayak R, Kothari V (2004) Extension and recovery characteristics of air-jet textured yarn woven fabrics. Indian Journal of Fibre and Textile Research 29: 62-68.

35. Nayak R, Chatterjee KN, Tanwar A, Gon DP (2007) Handle and comfor properties of Polyester/Viscose suiting fabrics. Man-Made Textiles in India 50: 288-292.

36. Khedher F, Dhouib S, Msahli S, Sakli F (2009) The influence of industria finishing treatments and their succession on the mechanical properties of denim garment. AUTEX Research Journal 9: 311

37. Nayak R, Kanesalingam S, Houshyar S, Vijayan A, Wang L, et al. (2016) Effect of repeated laundering and Dry-cleaning on the thermo-physiological comfort properties of aramid fabrics. Fibers and Polymers 17: 954-962. 